\title{
CULTURA Y POBREZA: ALCANCES CONCEPTUALES ${ }^{1}$
}

\section{Culture et pauvreté: atteite conceptuales}

\author{
Francisca Márquez Belloni²
}

Du moment ou un indigent est inscrit sur la liste des pauvres de sa paroisse il peut sans doute réclamer des secours: mais qu 'est- ce que l'obtention de ce droit, sinon la manifestation authentique de la misere, de la faiblesse, de l'inconduite de celui qui en est revêtu? (Alexis Tocqueville, Memoire sur le pauperisme, 1835).

\section{Resumo}

Dois grandes aspectos são analisados no texto: $O$ primeiro diz respeito à pobreza em si, o seu caráter e os parâmetros de determinação da condição de pobre; O segundo aspecto analisado refere-se às implicações sociais da pobreza, como é o caso de questões de identidade das pessoas (com implicações sobre a busca da integração, do reconhecimento e do processo educacional), a deteorização dos laços sociais, a pobreza e cidadania, o status social e a pobreza e a relação entre o trabalho e a pobreza.

Palavras-chave: Pobreza; Educação; Cidadania; Laços sociais.

\section{Résumé}

Deux grands aspects sont analysés dans le texte: le premier s' agit de la pauvrété en soi, son caractère et les paramètres de détermination de la condition de pauvre; le second aspect analysé s' agit des implications sociales de la pauvrété, comme le cas des questions d' idéntité des personnes (comme les implications sur la recherche de l' intégration, de la reconnaissance et du processus éducationnel), la détéoriration des liens sociaux, de la pauvrété et la citoyenneté, le status social, la pauvrété et la rélation entre le travail et la pauvrété.

Mots-clé: Pauvrété, Citoyenneté ; Liens sociaux.

1 Este articulo presenta algunos resultados de la Investigación Fondecyt n. ${ }^{\circ}$ 1020318, "Trayectorias de movilidad social de familias pobres urbanas: repuestas estatales a historias singulare."

2 Doutora em Sociologia, professora e pesquisadora na Universidad Academia Humanismo Cristiano - Chile. 


\section{De pobres y asistidos - La pobreza como categoría absoluta}

La definición de pobreza que ha dominado durante las últimas décadas considera como referencia la capacidad que tienen los hogares y las personas de satisfacer una canasta básica de alimentos, calculada sobre bases nutricionales y otras necesidades básicas. El indicador utilizado para medir esa capacidad son los ingresos monetarios a que aquellos acceden. De allí su denominación de enfoque biológico y absoluto de la pobreza, por un lado, y del ingreso, por otro. (BARROS et al. 1996).

A partir de los ingresos se definen los umbrales absolutos que consagran situaciones y categorias diferentes en cuanto al grado de subconsumo o privación: los indigente, los pobres y los no pobres. ${ }^{3}$

Esta definición de "líneas" sociales -indigentes, pobres y no pobresha servido de base para medir y evaluar la evolución económica en términos de su éxito o fracaso en superar dichas situaciones, así como de fundamento para la formulación de las políticas de superación de la pobreza orientada a aquellos segmentos sociales más desfavorecidos para participar en el mercado. En pro del principio de igualdad de oportunidades, la acción del Estado se orienta por tanto a facilitar y subsidiar la integración de este segmento de pobres en el mercado.

Un aspecto teóricamente crucial en la idea de que la "pobreza" es el objeto de la política social, y representa una modificación importante en los supuestos de la teoría económica liberal, es la existencia en las sociedades de un estrato identificable dentro del continuo de la distribución de los ingresos que quedaría fuera de la acción de la "mano invisible". ${ }^{4}$

La utilidad de una definición absoluta de pobreza, esto es de una línea bajo la cual se puede hablar de pobres e indigentes, permite establecer un punto de referencia para establecer las bases de un "derecho de los pobres"; y, asimismo fijar el gasto social público. El concepto de línea de la pobreza permite delimitar las necesidades que se requieren para superar la pobreza, pero a su vez delimita los ámbitos que ocuparan a las politicas sociales para el logro de este objetivo.

3 Los indigentes, segmento de hogares y personas cuyos ingresos per capita no son suficientes para asegurar una canasta básica de alimentación para cada uno de sus miembros; los pobres, segmento conformado por todos los hogares cuyos ingresos per capita bastan para satisfacer la canasta básica de alimentos, pero que igualmente tienen limitaciónes para satisfacer el conjunto de sus necesidades básicas porque no alcanzan a completar un ingreso monetario igual o superior al doble del valor de una canasta básica de alimentos en las areas urbanas o 1.75 veces en el sector rural.

4 J.Martínez y M.Palacios, 1995. 
La existencia de una línea de la pobreza posibilita también definir una situación de egreso y de término a la intervención del Estado. Desde el momento en que una cantidad de la población definida como pobre logra alcanzar un nivel de ingresos que le permite satisfacer sus necesidades y ubicarse por sobre la línea de la pobreza, el Estado podrá terminar todo tipo de intervención compensatoria.

\section{La pobreza como subcultura}

En los enfoques modernos sobre la pobreza, la degradación se entiende no sólo desde categorías éticas, sino también y principalmente en relación al conjunto social y económico que la genera. Los análisis basados en las condiciones de las estructuras de clases - e inspirados en los diagnósticos de los años 60- mostraban el aspecto degradante de la pobreza como un fenómeno de desigualdad social, por el cual los estratos más bajos quedaban segregados y marginados del resto de la sociedad.

En oposición a los enfoques estructuralistas que ubicaban la pobreza creciente de los países del sur en la dependencia de estos con el norte y la conformación de estructuras sociales altamente excluyentes, surge en los años sesenta la tesis de la "autorreproducción" de la pobreza ${ }^{3}$. El carácter desviante de los comportamientos de los pobres se explica por la existencia de valores y modelos culturales distintos a los dominantes en la sociedad. Se hablará así de subcultura de la pobreza, valores y modelos de comportamiento transmitidos intergeneracionalmente y que estarían a la base de la baja posición de las personas en la estructura social.

Distanciadas de las viejas explicaciones de la desigualdad social de los años 60, las políticas sociales de las últimas década, han basado parte importante del fundamento de su intervención, en un contexto de economía de mercado, en esta proposición histórica y antropológica de la autorreproducción de la pobreza.

En los términos de las políticas sociales: bajo un cierto umbral de ingresos (la línea de la pobreza) las personas pobres no estarían en condiciones de visualizar ni aprovechar las oportunidades que el mercado les ofrece. Fijados en una situación de sobrevivencia, las familias tenderían a acumular, producir y reproducir intergeneracionalmente pautas de comportamientos y valores propios a una "cultura de la pobreza", esto es, de la desesperanza y el dejarse estar. Sin la intervención del Estado, por tanto, no hay posibilidad de romper este circuito de la reproducción de la cultura de la pobreza y la falta de motivación y capacidad de iniciar procesos de movilidad social. En otros términos, iniciar carreras de movilidad social o simplemente superación de la pobreza, exige tener la capacidad de competir y desplegar habilidades y prác- 
ticas que carecerían las personas ubicadas bajo un determinado umbral de ingresos.

El paradigma de la "subcultura de la pobreza" inspira por cierto las políticas sociales normalizadoras y disciplinadoras de los años 80. El énfasis en la integración social será leido no solo como integración a mejores oportunidades laborales sino también como la creación de "conductas" y motivaciones hacia la adscripción a los valores de la integración y la movilidad social.

El postulado es, pues, que la vida bajo el límite absoluto de ingresos que establece operativamente la "línea de la pobreza" genera a nivel de los individuos una respuesta de desesperanza aprendida respecto a las probabilidades de movilidad social ascendente. ${ }^{5}$

No existe, sin embargo, evidencia que respalde la idea de que la orientación hacia la movilidad social encuentre su "punto de partida" (o se gatille ) al traspasarse el límite que establece la llamada "línea de pobreza".

Tampoco existe evidencia empírica alguna que avale la proposición de que el estrato pobre comparta una sola "cultura", o de que los límites del conjunto que participa de la "cultura de la pobreza" se correspondan de manera efectiva con los límites del "estrato" pobre.

La superposición entre el estrato pobre y la cultura de la pobreza es una mera suposición que se adopta para el efecto de dar justificación a la definición de un grupo-objetivo de la ayuda estatal. Sin embargo, esta suposición aspira a llenar un vacío real en la construcción teórica del concepto, aunque lo haga de un modo distorsionado: si la pobreza ha de ser motivo de atención continuada e institucional por parte del Estado, en efecto, es porque se reconoce la existencia de un hiato entre la orientación a la movilidad social y la probabilidad efectiva de movilidad. ${ }^{6}$

Lo importante, en términos de estrategia y diseño de política, es no olvidar que la pobreza, entendida ya sea como carencia de ingresos o disposición cultural, es por sobre todo una construcción social de largo aliento. La desesperanza, las viejas y arraigadas prácticas clientelares, y los habitus (diría Bourdieu) de la pobreza no se transforman por la simple voluntad o esfuerzo de las personas, tampoco por una cartera de subsidios y un contrato firmado entre la familia y algún esforzado trabajador social. El diseño de políticas y programas de corto alcanze desconocen no solo que las prácticas y los estilos de vida no se cambia de un año para otro; sino también, que las condicionantes estructurales, económicas, culturales y sociales, pueden pesar tanto como las propias convicciones al momento de actuar y construir la propia trayectoria vital.

\footnotetext{
${ }^{5}$ O. Lewis, 1965.

${ }^{6}$ Martinez y Palacios, 1995.
} 
El Estado se enfrenta también a una fuerte transformación sociológica. Como bien advierten diversos estudios, sus "sujetos" cambiaron. El Estado providencia estaba organizado para tratar los problemas de poblaciones relativamente homogéneas, de grupos o clases; pero ahora debe encargarse de individuos que se encuentran en situaciones que les son particulares. Para analizar lo social, hay que recurrir cada vez más a la historia individual antes que a la sociología.?

Los desocupados no constituyen poblaciones en el sentido tradicional de la acción social. Los individuos a los que conciernen tampoco son un grupo en el sentido sociológico. Más que compartir cierto perfil de orden biográfico sus vidas han realizado trayectorias que presentan cierta homología: sucesión idéntica de rupturas sociales o familiares, mismo tipo de quiebres... Son las "formas" de su historia y no sus características sociales y laborales las que los acercan. Es por eso que no constituyen ni una comunidad social ni un grupo estadístico. ${ }^{8}$

Esto que hoy resulta cierto para lo social en general, pareciera ser más evidente para quienes comparten los rasgos de la exclusión social que por definición resulta de un proceso de desagregación. Los excluidos de hoy, los pobres de la modernidad no constituyen un orden, una clase, un cuerpo o una categoría social. Ellos dan cuenta más bien de una falta de tejido e identidad social que permita reconocerlos como un todo.

\section{La pobreza como no-ciudadanía}

Lo cierto es que independientemente de la operacionalidad del concepto de pobreza absoluta, carencias medidas estadísticamente, la conceptualizacion en boga en torno a la pobreza reemplaza los antiguos actores sociales populares por una categoría genérica de "pobres" y en la cual la responsabilidad es devuelta a cada uno individualmente.

La categoría absoluta de "pobreza" permite por sobre todo colocar el problema de la política social fuera de: a) la consideración de la diversidad cualitativa de la pobreza, por tanto de su relatividad; b) asi como de la desigualdad, esto es del campo de relaciones de los más pobres con el resto de la sociedad.

Que la pobreza sea un estrato social (definida a partir de la variable ingresos) o una categoría estadística no lo transforma por cierto, en una categoría social, por el contrario, ella no es más que una pre-nocion, en el sentido

7 Martínez y Palacios, 1995.

8 Paugam, 2002; Garretón, 19..; Rosanvallón, 1999. 
de Durkheim". Bajo la llamada "linea de la pobreza" encontramos grupos sociales tan diversos como mendigos, mujeres solas, ancianos, cesantes, sin casa, niños, campesinos...El estrato de la pobreza reune tantos individuos como sea posible imaginar, pero cuyo único punto en común es la carencia que finalmente solo los vuelve merecedores de un trato diferencial por parte del Estado.

Como ya señalaba Simmel a principio del siglo XIX, ... Ce qu 'il y a de plus terrible dans la pauvreté est le fait qu 'il y a la des êtres humains qui, dans leur position sociale, sont pauvres et rien que pauvres." ${ }^{10}$ Así entendido, ser pobre consiste precisamente en la negación de sí mismo, solo carencia.

Desde el momento que la pobreza es solo carencia, combatida y juzgada intolerable, su status social no puede sino ser desvalorizante y estigmatizante. La desclasificación social que introduce la clasificación estatal de la pobreza la aproxima a una noción de no-ciudadanía: pobre es aquel que está fuera del mercado y de la sociedad. Sin los lazos básicos, el pobre no puede sino vivir como un extranjero al resto de la sociedad, en el aislamiento a través del encierro, el apartheid y el guetho. El disimulo de su inferioridad estigmatizante y el miedo de los otros está a la base de toda situación y experiencia de pobreza.

En las sociedades modernas, la pobreza no corresponde solo al estado de una persona que carece de bienes materiales, ella corresponde también a un status social especifico, inferior y desvalorizado que marca profundamente la identidad de quienes la viven. Este elemento no es del todo nuevo en el debate sobre la pobreza. Tanto el programa filantrópico del siglo XIX como la doctrina social del cristianismo colocaban en primer plano el aspecto de la degradación moral que la miseria determinaba en la existencia humana. Históricamente, el denominador común de los elementos que hacían de la miseria un fenómeno social lo constituyó la función degradante de tal estatus. ${ }^{11}$

\section{La pobreza como un frágil lazo social}

George Simmel, en un breve texto titulado Der Arme ${ }^{12}$ escrito en 1908, se plantea justamente la ambigüedad de la noción de pobreza como categoría sociológica. Para Simmel, la pobreza, es no solamente relativa, sino que ella también se construye socialmente. El significado de la pobreza, es aquel que la sociedad le otorga. El enfoque teórico simmeliano, fundamental-

\footnotetext{
9 P.Rosanvallón, 1999; V.Espinoza, 1999; Paugam, 2000.

10 E.Durkheim.1973.

11 G.Simmel, 2002,p.101.

12 B.Geremek, 1989, Paugam, 2002.
} 
mente relacional, contribuye así a evitar una definición substancialista del pobre, reubicando la mirada sobre la relación de interdependencia con la sociedad y en especial el Estado. ${ }^{13}$

En Simmel, es la relación simultánea de asistido y temido que da forma a la figura del pobre en nuestra sociedad. Sin desconocer su carácter de "indeseado", inútil, miserable... reconoce que en la relación de asistencia tanto el pobre como el donante se encuentran en una relación social. De allí la invitación a comprender las formas sociohistóricas de la red de interdependencia que se construye entre los pobres y el resto de la sociedad. Aquello que es sociológicamente pertinente no es la pobreza en tanto tal, sino las formas sociales que ella adquiere en la sociedad en un momento específico de su historia. ${ }^{14}$ Esta sociología de la pobreza se vuelve en realidad una sociología del lazo social. ${ }^{15}$

Simmel precisa una definición: "les pauvres, en tant que catégorie sociale, ne sont pas ceux que souffrent de manques et de privations spécifiques, mais ceux qui recoivent assistance ou devraient la recevoir selon les normes sociales. Par conséquent, la pauvreté ne peut, dans ce sens, être définie comme un état quantitatif en elle-même, mais seulement par rapport a la réaction sociale qui résulte d une situation spécifique."

Los pobres, asi definidos, no están fuera de la sociedad, sino en ella. Ellos ocupan por cierto, una posición particular por el hecho de encontrarse en una situación de dependencia en relación a la colectividad que los reconoce y los trata como tal. A semejanza de la figura del extranjero, el pobre comparte el atributo de distancia y proximidad al todo social, posición ambigua y nunca resuelta.

El principio de la asistencia social, o de la política social, hace evidente en relación a los pobres, las tensiones y los desequilibrios, las rupturas que amenazan el sistema social en su globalidad, pero también deja entrever el margen de maniobra que el pobre en tanto sujeto logra desplegar en su ir y venir como dependiente de un sistema social.

Es justamente en estas relaciones que se establece un sistema estable de negociaciones entre responsables y clientes de la acción social. Aún asi, la posibilidad de maniobrar la relación, no puede ser sobreestimada, ella siempre se realiza en el marco de condiciones exigentes. Pero transformando por el discurso el sentido de la experiencia, evitando a aquellos con los cuales busca diferenciarse, presentando a los trabajadores sociales la imagen de si que atraera la simpatia sobre ellos, reconstituyenod jerarquias sutiles al interi-

13 El Pobre

14 R.Castel recupera esta noción a través de su concepto de "desafiliados", es decir, le "desafilie" seria quien ha roto con todos los vínculos de protección social, incluyendo los más cercanos.

15 Paugaum et Schultheis, 2002. 
or de un mundo globalmente descalificante, los asistidos, logran de alguna manera una forma de liebrtad. La figura del asistido, a pesar del escaso margen de maniobra, revela como cada uno debe finalmente gestionar sus fracasos y caidas sociales. ${ }^{16}$

En otros términos, podríamos decir, que se deja de ser pobre cuando se deja de ser "asistido", cuando su lazo con el todo social deja de ser intermediado y "custodiado" por el Estado y el sujeto emerge. La autonomía en el vínculo social es esto, la ruptura de la relación de dependencia con el Estado y por tanto, la recuperación plena de su ciudadanía se logra solo cuando se deja de ser un "asistido".

Aquello que es sociológicamente pertinente por tanto, deja de ser la pobreza en tanto que pre-noción, sino las formas institucionales que adquiere esta situación en nuestras sociedades. Si la pobreza constituye una condición socialmente reconocida, los pobres constituyen un conjunto de personas cuyo status social es definido, por un conjunto de instituciones especializadas de la acción social que los designan como tales. ${ }^{17}$

La relación entre pobreza y cultura/ identidad por ende debe ser abordado en esta relación compleja de doble carencia: esto es, falta de la integración funcional y falta de afiliación social y/o cultural:

\begin{tabular}{|l|l|l|l|}
\hline & & \multicolumn{2}{|l|}{$\begin{array}{l}\text { Falta de autonomia material } \\
\text { Integración funcional }\end{array}$} \\
\hline \multirow{2}{*}{$\begin{array}{l}\text { Falta de afiliación social } \\
\text { Integración cultural }\end{array}$} & & SI & NO \\
\cline { 2 - 4 } & SI & Pobres & $\begin{array}{l}\text { Guetos } \\
\text { Tribus urbanas }\end{array}$ \\
\cline { 2 - 4 } & NO & Vulnerables & Integrados \\
\hline
\end{tabular}

${ }^{16}$ En una línea similar, el enfoque téorico de redes sociales intenta resolver el problema de la construcción de categorías basadas en atributos individuales, a partir del análisis de kas relaciones entre individuos. Las estructuras se corresponden con las pautas de relaciones recurrentes en aun grupo social, antes que a agrupacione de individuos con caracterpiusticas similares. La definición de categorías sociales se hace así compranado el conjunto de relaciones sociales de diversos individuos, principalmente en términos de su estructura. En este sentido, dos individuos pertenecen a una misma categoría sólo cuando sus relaciones sociales se intersectan de tal forma que los hacen estructuralmente equivalentes. De esta forma, un pobre sólo es igual a otro pobre, cuando las relaciones sociles de ambos tienden a superponerse y no sólo cuando pertenecen a la misma categoría de ingreso. V.Espinoza, 1999.

${ }^{17}$ D.Schnapper, 2002. 


\section{La pobreza y el status del sujeto}

Si el pobre, se define fundamentalmente por su carencia y necesidad de ser asistido, es posible hablar de él como sujeto? La pregunta es especialmente relevante si por sujeto estamos entendiendo "la capacidad del individuo de construirse su identidad"18.

Es decir, la capacidad de ser "sí mismo" en la relación con los otros; que permita conciliar dos aspectos esenciales:

a) el sentimiento de realización, la identidad para sí;

b) el reconocimiento social, la identidad para los otros.

La identidad realizada y el proyecto identitario surgen finalmente del trabajo que cada individuo realiza para concordar y disminuir la distancia entre lo deseado y lo asignado ${ }^{19}$

El asistido es por definición quien merece ser ayudado por el Estado; es el excluido, el desafiliado de R. Castel, el que carece de los vínculos básicos para hacerse de un ingreso que le permita resolver sus sobrevivencia e iniciar una trayectoria de movilidad social. Y en esto reside justamente el desafío al que se ve confrontado el pobre en su relación cotidiana con la sociedad. La superación, es decir, la transformación de su condición de dependencia es justamente el acortamiento de la distancia entre lo deseado y lo posible. La expresion "trabajo de la identidad" tiene este sentido; el trabajo permanente de los individuos por conciliar y aproximar este deseo de sí y las expectativas de los otros. Esfuerzo permanente, que en el caso de quienes se encuentran en una situación de dependencia y pobreza es especialmente difícil de alcanzar. Los soportes para construir este sujeto son por cierto, frágiles para quien vive en situación de pobreza en una sociedad marcada por la desigualdad de oportunidades.

Sin embargo, el margen de maniobra siempre existe. Tras todo asistido, por muy dependiente que este sea del Estado, hay una historia individual, que se remite y adscribe a un tiempo y a un espacio específico. Y es justamente esta inscripción social, cultural e histórica la que le otorga un lugar, una identidad, una posibilidad y una impronta a la biografía de cada sujeto, por muy pobre que este sea.

Especificar en qué la identidad está determinada por la posición del individuo en la estructura social, no niega su singularidad. En sociedades con crecientes grados de desigualdad, la experiencia social e individual no está asegurada, porque ella ya no es una; son los individuos quienes deberán

18 S. Paugam, 2002.

19 G.Bajoit (2002) utilizará el concepto de "gestión de las tensiones existenciales", he preferido sin embargo, hablar de "procesos de construcción identitaria", y evitar de este modo el término "gestión" por la asociación que tiende a tener con la administración racional de recursos. 
construir el sentido de sus prácticas. Esta diversificación de la experiencia junto a las exigencias de individualización y subjetivación que nos impone, surge hoy como la forma de la experiencia moderna. No es de extrañar que las referencias identitarias sean múltiples, poco consistentes y a menudo débiles a nivel colectivo. Los individuos deben realizar ajustes permanentes para intentar mantener una cierta coherencia en un medio ambiente que requiere de respuestas rápidas, oportunas y adecuadas.

\section{Construcción identitaria y sujeto pobre}

\section{Transformaciones identitarias}

En la literatura sociológica el estudio de la movilidad y las condiciones que facilitaban la reproducción de la pobreza ha sido fundamentalmente abordado desde las condiciones estructurales que favorecen las posibilidades de ascenso o descenso social de las personas.

La pregunta que pareciera hoy instalarse en la discusión es si, dadas las profundas y aceleradas transformaciones de nuestra sociedad y economía, no habría tal vez que abrir la mirada y el análisis hacia cómo el cambio social y estructural se instala en la vida y la cultura de los sujetos y sus familias...

Lo cierto es que las características que asumen las transformaciones de la estructura social y ocupacional, dan cuenta que tener un trabajo asalariado ya no supone ser parte de una red de seguridad social ni tampoco dejar de ser pobre. Ser asalariado y vivir en condiciones de vulnerabilidad o pobreza es una realidad en muchos paises. En la última década, al igual como sucede en el resto del continente, Chile muestran un progresivo debilitamiento de estas coordenadas de seguridad básica.

Debilitada la sociedad salarial y sus certezas básicas, la posibilidad de iniciar procesos de movilidad social ascendente no parece asociarse hoy en día tanto a la adscripción a una determinada categoría o posición en la estructura ocupacional, sino a la capacidad de los sujetos de construirse una red de protección y seguridad social que no solo los cobije sino también les permita lograr mejores niveles de vida.

Y aunque los factores que determinan los caminos hacia el empobrecimiento y la exclusión social se construyen y superponen a lo largo de la vida de cada sujeto y de generación en generación, los rápidos procesos de modernización de nuestros países unido a las transformaciones de la estructura social y la progresiva consolidación de la desigualdad, hacen necesario incorporar al impacto de las política sociales para revertir dichos procesos, la pregunta por la capacidad de los sujetos para construirse a sí mismos en este contexto. 
En efecto, diversos estudios ${ }^{20}$ indican que la movilidad social depende de

a) las condiciones objetivas como es la incorporación al mercado de trabajo y el acceso a las oportunidades;

b) y las dimensiones subjetivas que inciden en la dinámica de la inserción social; la reflexividad, la capacidad de innovar y crear son hoy recursos centrales al momento de emprender una trayectoria laboral ascendente. La capacidad del individuo para buscar sus propias respuestas se ha vuelto central, en una sociedad donde los modelos de integración ya no están asegurados.

En el contexto de la transformaciones de las relaciones del trabajo y el progresivo debilitamiento del Estado providencia, también las certezas en torno a las identidades y al propio proyecto vital han sufrido transformaciones.

En síntesis, a individualización de lo social tiene repercusiones sobre la experiencia individual, repercusiones que no solo aluden a cuestiones de orden económico, tecnológico e industrial, sino que designan también los efectos de un proceso de desinstitucionalización de los marcos colectivos que estructuraban la identidad social e individual (familia, escuela, tradiciones, religión) y que por ende, obligan a repensar las nuevas dimensiones que adquieren los procesos de conformación de las identidades en las sociedades contemporáneas.

Efectivamente, si antaño el que era obrero se sabía parte de una cultura y un proyecto de movilidad colectiva, hoy el antiguo obrero sabe bien que es él quien debe resolver y asegurar su integración social. En otros términos, si antes el hijo de minero sabía que su destino era serlo igual que su padre, hoy ese mismo hijo sabe que la respuesta por su futuro está pendiente; y que su búsqueda es una trayectoria fundamentalmente solitaria. Los modelos de integración ya no parecieran estar asegurados, lo único definitivo es la capacidad de cada individuo para buscar y construir sus propias respuestas y la de su colectividad.

En otros términos, podríamos decir que el malestar pareciera surgir de una contradicción entre lo deseable y lo posible, en la evidencia que la brecha entre ambos ha crecido. Acortar la brecha, es decir, hacer posible la realización del propio proyecto vital, se asocia estrechamente a la capacidad

20 Estas tres dimensiones se reconocen en la mayor parte de la literatura sobre identidad; la identidad es por definición la construcción y tensión permanente entre la identidad para sí/ la identidad para el otro; cuya expresión puede concretarse en términos de una realización identitaria o bien permanecer como proyecto futuro, postergado o dificilmente alcanzable. Los análisis sobre la identidad ponen siempre a prueba esta matriz tensiones en los procesos de construcción identitaria. G.Bajoit, 2002, Belin, 1995; J.Larraín, 2000. 
de los sujetos de construir una experiencia social que logre combinar y transitar adecuadamente entre las construcciones sobre sí mismo y aquellas que operan en torno a él; la importancia de las tensiones estructurales y de los soportes básicos a la realización identitaria no es menor.

Las historias de reproducción de la pobreza remiten necesariamente a la pregunta si acaso estas posiciones en el mercado y la estructura social representan una condena o si bien las personas que están en una u otra posición pueden cambiar de escenario. Efectivamente en condiciones de desigualdad, el margen de maniobra parece ser escaso; pero las biografías muestran también que la propia posición no siempre indica una condena.

\section{El trabajo de sí mismo en la pobreza}

En términos simples, las historias y trayectorias de los más pobres a menudo hablan de postergación y resignación. Es decir, de la dificultad para concretar o poner en acción el propio proyecto vital; proyecto que como sabemos no siempre responde a lo que se soñó para sí mismo, pero proyecto al fin. En las vidas postergadas sus protagonistas perciben que entre lo deseado para sí y lo logrado existe un abismo infranqueable y en el mejor de los casos, difícil de sortear.

La historia de muchos pobres, es un buen ejemplo de como la realización de la propia vida se construye en una compleja transacción entre: las oportunidades que la propia posición y circunstancias van otorgando y la capacidad del sujeto de valerse y poner al servicio de sí mismo los recursos que esta estructura de oportunidades le ofrece.

En esta búsqueda permanente, el peso de la historia y de la cultura sobre cada sujeto puede ser más o menos importante, pero el individuo no se reduce nunca totalmente a estas condicionantes, sino que él responde, construye y crea de acuerdo a su propia lógica respuestas a su situación.

La mayor o menor realización de la propia vida parece estar estrechamente vinculada a la resolución de esta tensión, entre las construcciones que un individuo tiene sobre sí mismo y aquellas que operan en torno a él, o a la interiorización que éste hace de ellas. Aún cuando la relación entre ambas dimensiones es estrecha (la imagen de sí es dependiente del reconocimiento del otro, y viceversa), ambas no tienen la misma significación.

El análisis de los itinerarios individuales, ilustra ampliamente la pertinencia de esta distinción. En los relatos de vida a menudo se descubren desesperados esfuerzos de los sujetos por romper con esta distancia entre la imagen de si y el reconocimiento que los otros hacen de ella. La exacerbación de esta distancia y la imposibilidad de romper con ella, abre espacio a la construcción 
de estigmas y estereotipos en los cuales los sujetos quedan fijados / congelados en la relación y la mirada del otro.

En síntesis, la realización del propio proyecto vital parece asociarse estrechamente a la capacidad de los sujetos de construir una experiencia social que logre combinar y transitar adecuadamente entre lo heredado y lo deseado.

Lo importante en términos de políticas sociales y educacionales es que la forma que cada uno, aún cuando pertenezca a una misma categoría social, resuelva esta tensión no será nunca similar; las lógicas del sujeto varían siempre;

entre conformismo o rebeldía/ ruptura cada sujeto deberá buscar los caminos para resolver la distancia entre lo deseado y lo posible. "Chacun se débrouille comme il peut, entre ce qu'il veut et ce qu'il doit, avec son mélange de vérité et de mesonge, de lucidité et de ruse, de droiture et de compromission. Pour rester sujet, il faut savoir tantôt fermer les yeux sur soi-même, tantôt les ouvrir. ${ }^{21}$

Es por medio de este proceso que los individuos construyen su identidad; identidad que cada uno buscará realizar concretamente en torno a su familia, a su trabajo, a su comunidad, al Estado, a su escuela, su barrio.... El trabajo sobre si mismo, la identidad, supone siempre un "trabajo con los otros", en relación a los otros, amarrando en vínculos sociales, y por tanto, comprometiéndose en lógicas de acción social.

Sobre un transfondo cultural, un tiempo y un espacio, cada individuo dotado de vínculos sociales, y una biografía propia, construirá su "experiencia social" en la cual se pondrá a prueba finalmente su capacidad de construir un proyecto identitario deseado.

\section{Identidad como búsqueda de integración y reconocimiento social}

Entre los más pobres, los asistidos, las orientaciones, las prácticas y trayectorias orientadas a la movilidad social y al mejoramiento de sus condiciones de vida, no pueden ser comprendidas al margen de estas dos dimensiones: la búsqueda de la integración y el reconocimiento social.

Integración funcional y reconocimiento social son dos dimensiones estrechamente vinculadas en las demandas hacia el Estado y la sociedad por quienes buscan construir un proyecto identitario que les permita escapar a su condición de asistidos y de pobres.

Las relaciones entre el reconocimiento social y la realización de sí

${ }^{21}$ Ver V.Espinoza, 2002; F.Márquez, 2002. 
mismo son complejas. Por cierto, la necesidad de reconocimiento social, de existir a la mirada del otro está a la base de la alteridad y la construcción identitaria. Paradojalmente, en los relatos de la pobreza, la dominación simbólica, la percepción de ser permanentemente estigmatizados y reprobados por ser aquello que son (ser de campamentos, ser pobres, ser asistidos), y a la vez la negación de salidas para dejar de serlo, es una constante. En los relatos y las historias de la pobreza, la descalificación social penetra la imagen de sí mismo, transforma y moldea la capacidad de acción; contradicción y tensión cotidiana con el entorno que no tarda en tener consecuencias identitarias y sociales.

Recurrir a la asistencia y a la ayuda estatal a menudo ha sido descrito como una experiencia humillante que introduce transformaciones en el itinerario biográfico de un individuo. La fecuentación regular de los servicios de acción social, es en efecto, expresión de dependencia e inferioridad social. La descalificación social de la que a menudo son objeto los más pobres de la sociedad, nos remite necesariamente a la lógica de clasificación de la cual son objeto y a los efectos que ello genera sobre el plano identitario.

La relación con la asistencia social por cierto, puede ser vivida como una ceremonia de degradación de sí mismo; la obligación o el deber de los "asistidos"a develar y mostrar los aspectos más intimos de su miseria, por cierto tiene consecuencias de humillación y degradación. Como señala Paugaum (2002), "l'aide aux pauvres implique toujours le contrôle des pauvres".

Las respuestas frente a la descalificación no son sin embargo, siempre iguales. La descalificación social no es siempre percibida, vivida ni asumida de la misma forma.

- Mientras para unos la descalificación y la estigmatización destruyen desde adentro y de manera casi imperceptible la rebeldía frente al otro;

- para otros, la descalificación del cual son objeto, despertará rabia y la "ruse" para dar respuesta y sortear la mirada invalidante.

- Mientras algunos preferirán resguardarse en los estrechos, pero seguros márgenes de la comunidad de iguales,

- habrá quienes en cambio, preferirán valerse de la mirada compasiva y caritativa para sobrevivir.

- Y habrá también, quienes humillados buscarán el camino para reivindicar un trato más digno por parte de la sociedad y el Estado. ${ }^{22}$

En fin, las respuestas frente a la descalificación social parecieran no tener límite...

El ejercicio de la violencia simbólica, esto es, de la imposición de un

${ }^{22}$ Bajoit, 2002. 
sistema de valores por medio de mecanismos a menudo "infantilizadores" y represivos ha sido señalado como uno de los rasgos característicos de la relación que las políticas sociales a través de sus operadores establecen con la pobreza.

La pregunta que se impone por tanto, es en que medida y a través de que mecanismos, los sujetos de asistencia social adhieren, negocian, se distancian de las normas y las lineas de acción que las políticas sociales les proponen o imponen. Para que la categoría social de "asistido" se active social y públicamente se requiere que las consecuencias prácticas se manifiesten. Es decir, que se establezca una relación concreta entre el trabajador social o un operador de programas sociales y el "pobre"; y que de esta relación surga un producto concreto como puede ser la obtención de un subsidio social. En estos términos, podríamos decir, que los beneficiarios de la acción social, participan también, en la definición de su status de "asistido" así como en la constitución de su identidad personal. Aceptando o rechazando las condiciones y la reglas de la intervención social de los trabajadores sociales sobre su vida privada, los pobres "colaboran" también en la construcción de este vínculo social. ${ }^{23}$

En estos términos, el análisis de la condición de precariedad social y económica del pobre es inseparable del análisis del proceso que este sigue en términos de intercambio y de construcción de respuestas a su condición de asistido. Como bien afirma V.De Gaulejac "Il s'agissait de mieux comprendre l'articulation entre les conditions objectives et les conditions subjectives dans les processus d'exclusion. Quelle est la part respective des déterminations sociales et des réactions des sujets concernés dans les dynamiques d'insertions ${ }^{24}$

"Quelles que soientles mesu res objectives, les dispositifs d'in tervention, les a mélioration institutionnelles ou légales, la nécessité première est de considérer autrui comme un sujet, même s'il peut paraître paradoxal de s'affirmer comme sujet de sa désinsertion. C'est pour cela que les questions de reconnaissance et de dignité sont aussi essen tielles. Il s'agit avant tout de préserver l'image de soi, quand bien même on est prêt pour ce faire à se couper des autres. La reconnaissance de l'autre comme sujet est au fondement du lien social. A penser la "réinsertion" uniquement sous l'angle objectif, en terme de revenu et d'emploi, on passe à côté d'un besoin primordial. Celui d'être considéré comme l'auteur de son existence, comme responsable de "ce que JE suis", comme sujet capable de faire des choix. Mieux vaut faire des choix négatifs que de ne plus pouvoir choisir. Lorsque l'individu se sent dans une impasse, lorsqu'il a le sentiment de ne plus avoir d'autres choix que celui de rompre et de se désin-

23 F. Márquez, 2002.

24 Paugam, 2002. 
sérer, alors il préférera quand même aller jusqu'au bout, jusqu'au fond du trou, plutôt que de renoncer à cette liberté fondamentale: pouvoir être sujet de son histoire. On voit ici l'importance qu'il faut accorder à l'affirmation de soimême." 25

De lo que se trata por tanto, es de privilegiar la interpretación comprensiva de las actitudes y representaciones individuales y colectivas, admitiendo que los más pobres poseen siempre un margen de autonomía que les permite interiorizar, refusar o negociar la definición social de su condición de "asistidos" ${ }^{26}$. Reconocer un margen de maniobra y autonomía sin embargo, no significa que ellos sean absolutamente dueños de sus destinos, los determinismos estructurales y los niveles de conciencia individual y colectiva están estrechamente interrelacionados.

\section{Referências}

BAJOIT, Guy. La mutation de la politique sociale dans les Etats néo-libéraux, Ponencia Seminario Politicas Sociales, Universidad Católica de Valparaiso, 2002.

, Guy. Tout change, 2002. (en imprenta)

BENGOA, J., F.Márquez y S. Aravena. La desigualdad: testimonios de fines del siglo XX, Santiago:SUR, 2000.

BENGOA J. 1995. La pobreza de los modernos. Santiago: SUR, Marzo. (Temas Sociales, 3).

BECK, U. La teoría del riesgo. Madrid:Anthropos,. 1997

BOURDIEU, P.La distinctio. Paris: PUF, 1987.

2001 .

Las estructuras sociales de la economía. Buenos Aires:Manantial,

25 V. de Gaulejac, I. Taboada Leonetti, La Lutte des places, Paris, Desclée de Brouwer, 1994.

26 V.De Gaulejac, 2002.

27 Esta línea de análisis ya estaba presente en Erving Goffman (1975) en sus estudios del estigma, la discapacidad y la identidad social. A través de sus observaciones, Goffman muestra como el estigmatizado, a pesar de la mirada ambivalente en relación a su propia persona, logra disimular y maniobrar con su estigma. A través del concepto de identidad personal, analiza el control que un individuo puede ejercer sobre la deficiencia y el descrédito que lo caracterizan. 
CASTEL, R. La metamorphoses de la question sociale. Paris: Fayard, 1995.

DE GAULEJAC, V. y I. TABOADA Leonetti. La Lutte des places. Paris: Desclée de Brouwer, 1994.

DE GAUlejaC, V. Etre sujet malgrais tout. Rev. Proposiciones, Santiago,v.34, 2002.

DURKHEIM, Emile. Les regles de la méthode sociologique. France: PUF, 1973.

EHREMBerG, A. La fatigue de etre soi meme. Paris: Odile Jacob, 1998.

GIDDENS, A. Modernidad e identidad del yo. Barcelona:Peninsula, 1995.

GEREMEK, Bronislaw, La Piedad y la Horca: Historia de la caridad y la miseria en Europa. Madrid; Alianza Universitaria,1989.

GEERTZ, Clifford.. Negara: El Estado - Teatro en el Bali del siglo XIX. Buenos Aires: Paidós Básica, 2000.

MÁRQUEZ, F. 2002. Los patios traseros de un Chile desigual, Ponencia Simposio "El Chile que viene", Universidad de Harvard y el David Rockefeller Center for Latin American Studies, Boston, 28 de febrero - 2 de marzo 2002.

Apuntes de terreno: los campamentos de Cerro Navia, En: Ciudadania y Desarrollo Local, IAF-SUR, Santiago: SUR,2002.

. La vida realizada -la vida postergada: la construcción biográfica en Chile. Revista Ciencias Sociales, Flacso, México, 2002.

La cultura y los procesos de movilidad social en los noventa: Santiago, Buenos Aires y Montevideo. Las desigualdades emergentes en América Latina, Rev. Proposiciones, v. 34, SUR, 2002.

. Trayectoria de vida y trabajo en sujetos pobres. Rev. Proposiciones, v. 32, SUR, Santiago, 2001.

. et al. Ciudadanía y Participación Social: Marco para una Ley de Participación en la Gestión Publica, Santiago: Secretaría General de Gobierno, 2001.

ROSANVALLÓN, Pierre. La nueva cuestión social: Repensar el Estado providencia, Buenos Aires : Manantial, 1998.

SALMAN, Ton. Politicos mentirosos y ladrones: Modelos políticos y modelos 
de organización barrial, los casos de Chile y Ecuador. Proposiciones, v.34, SUR, 2002.

SENNET, R. La corrosión del carácter. Barcelona; Anagrama, , 2000.

SIMMEL, George. Les Pauvres. France: PUF, 2002.

Recebido em 7/7/03

Aprovado em 13/10/03 